\title{
Erratum to: AutoPlay: Unfolding Motivational Affordances of Autonomous Driving
}

Sven Krome, Jussi Holopainen and Stefan Greuter

\section{Erratum to:}

Chapter 18 in: G. Meixner and C. Müller (eds.), Automotive User Interfaces, Human-Computer Interaction Series, DOI 10.1007/978-3-319-49448-7_18

The original version of the book was inadvertently published without removing Table 18.2 in Chap. 18. The erratum chapter and the book have been updated with the change. 